\title{
The Numerical Analysis of Fault-Induced Mine Water Inrush Using the Extended Finite Element Method and Fracture Mechanics
}

\author{
Qinglong Zhou $^{1,2} \cdot$ Juan Herrera ${ }^{1} \cdot$ Arturo Hidalgo $^{1,2}$
}

\begin{abstract}
Fault activation caused by construction, earthquakes, or mining can produce disastrous water-inrush episodes in underground mines. Fault activation is generally caused by stress concentration at the fault tip, so in this study, a computational model of a typical underground stope with a hidden fault was established to quantitatively assess the magnitude of the stress concentration of the stress fields of the fault-tip. Numerical simulation was performed using the extended finite element method and fracture mechanics. Stress intensity factors, which represent the magnitude of the stress concentration, were obtained using the interaction integral method to quantitatively evaluate the tip fields and assess the possibility of fault activation. The mining depth, fluid pressure, fault dip, and fault length were analyzed and the advance of a working face was simulated to determine whether underground mining would cause fault activation.
\end{abstract}

Keywords Fault activation - Modeling underground mining $\cdot$ Stress intensity factors $\cdot$ Aquifer $\cdot$ Stress concentration

Qinglong Zhou

zhou198773@gmail.com

1 Departamento de Ingeniería Geológica y Minera, ETS de Ingenieros de Minas y Energía, Universidad Politéncia de Madrid, C/Alenza 4, 28003 Madrid, Spain

2 Center for Computational Simulation, Universidad Politécnica de Madrid, Madrid, Spain

\section{Introduction}

In mining and excavation, complex hydrogeological conditions can cause serious water inrush accidents, in which a significant amount of water can suddenly invade an underground working space, flooding tunnels, shafts, or a whole mine face. More than 10,000 people have been killed due to mine inundation and inrush accidents in the United States, Australia, China, Poland, and India since the beginning of the twenty-first century (Detle 2012; Przemyslaw 2011; Zhang 2005). In China, 306 water accidents have occurred in various coal mines and resulted in 1325 deaths from 2006 to 2010. The mechanisms of water inrush are still not well understood, and inrush accidents still frequently occur in developed counties such as China and India every year.

Water inrush events are difficult to predict because the water sources and conduits that lead to inrushes are complex and variable. Water can flood from surface water bodies, aquifers, flooded tunnels, or any underground water reservoirs, and geological structures such as fractures, pores, geological contacts, and tectonic faults are all potential conduits (Chen and Hu 2011; Rapantova et al. 2012). Among these potential conduits, geological faults are the most common structures that cause such accidents; in China, up to $79.5 \%$ of inrush events in mines are associated with geological faults (Bu and Mao 2009).

The classical finite element method (FEM) and FEMbased simulation are the primary approaches that have previously been used to study the mechanisms of faultinduced water inrush. Odintsev and Miletenko (2015) attributed the inrush events to spontaneous hydrofracturing of the surrounding rocks, using the FEM to simulate an established hydrofracture model. Their study showed that inrush will occur when the fracture grows under the coupled forces of underground water pressure and the 
mining-induced stresses, and they proposed that fracture growth mainly occurs in two ways, the fracture propagation at fracture tip and the fracture opening throughout the length of the fracture. Using FEM-based simulation software such as COMSOL multiphysics and FLAC, researchers (Huang et al. 2012; Wang and Park 2003; Wu et al. 2004) discovered that although water-conducting and non-conducting faults may eventually be conduits for water inrush at various locations, conduit formation mechanisms are the same; they are due to fault extension under natural and mining-induced stresses. They also observed that the geological features of a fault highly influence conduit formation; for example, a bigger dip angle is less prone to inrush, whereas a larger fault throw is more likely to cause it.

Several studies (Liu and Hu 2007; Motyka and Bosch 1985; Zhu and Wei 2011) have simulated a fault-induced water inrush with more complicated models. For example, coupled solid-liquid models were established to understand the complex hydro-mechanical nature of an inrush. According to Lu and Wang (2015), fractures progressively develop in the floor strata as mining advances, and the deepest fractured zone appears under both sides of a mined-out area. Lu also postulated that there are three stages for the fracturing evolution of a fault, the quiet period, the active period, and the eventual eruptive period.

According to Li et al. (2011), mining-induced stresses concentrate stress within the region adjacent to the fault, thereby activating it. Based on the rock damage, they classified the floor into three zones: the mining-induced fractured zone, the intact zone, and the fault reactivation zone. Also, it was assessed that water inrush prediction requires determining whether the mining-induced fractured zone is connected with the fault reactivation zone. To determine the water pressure resistance of the fractured zone, a field measurement was conducted by Liang et al. (2015).

Numerical simulation techniques (i.e. classical FEM, FEM-based simulation software, and coupled models) were very useful in all of these studies. The main drawback of these numerical methods is that they are not suitable for problems with discontinuities, which appear whenever faults are considered in a geological model. This paper overcomes this difficulty by using the extended finite element method (XFEM) (Belytschko and Black 1999; Christophe and Nicolas 2000; Nicolas and Belytschko 2002), which was introduced to establish a fault-induced water inrush computational model by combining fracture mechanics (Anderson 1995) and the interaction integral method. Stress intensity factors (SIFs) at fault tips can be considered the main reasons to evaluate the potential of fault activation and the likelihood of water inrush.

\section{The Establishment of a Computational Model}

When huge tensions and compressive stresses are generated, relative movement and compression of strata can occur. Strong movement and friction of strata can lead to a fault zone that is predominantly oriented parallel to the fault plane (Fig. 1). The fault zone consists of two main hydromechanical units: the fault core zone (FZ) and damaged zones (DZ) (Caine et al. 1996; Gudmundsson et al. 2010; Sian et al. 2011). Highly permeable structural elements, such as fault gouge and fault breccia within the fault core, can cause a fault zone to act as a conduit for fluid flow (Bense and van Balen 2003; Rawling et al. 2001). The DZ are primarily composed of sets of fractures that can enhance FZ permeability relative to the core and the undeformed protolith (Caine et al. 1996; Goddard and Evans 1995). The FZ is a typical waterbearing structure (Sameh and Broder 2012), but its high permeability increases its hydraulic conductivity, causing water inrush incidents.

\section{The Establishment of a Fault-Induced Water Inrush Model}

The types of faults found in engineering projects differ. Before engineering activities start, large visible faults are typically recorded in detail during geological surveys and used to develop a plan to prevent water inrushes. However, small undetected faults or those to which enough attention was not paid due to technical limitations or

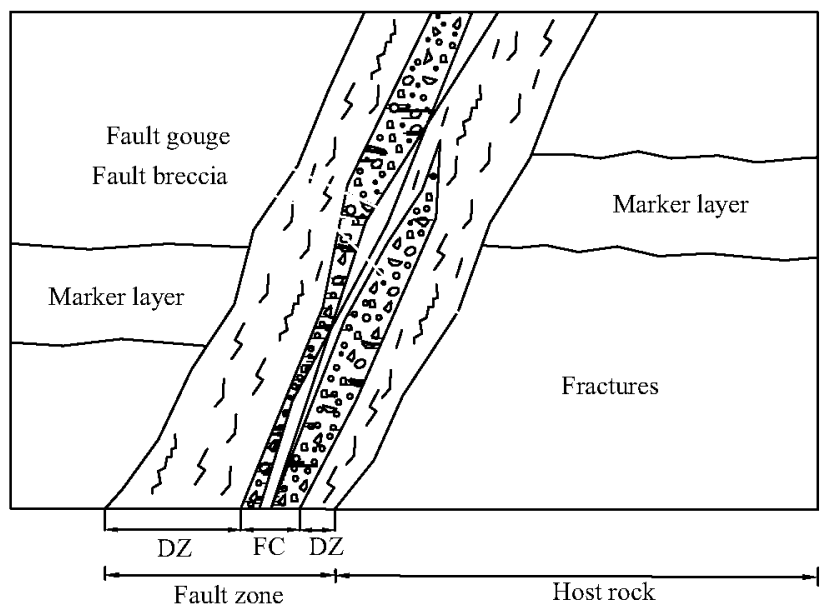

Fig. 1 Typical structural elements of a fault zone, generally it consists of two parts: damage zone (DZ) and fault core (FC), fault gouge and fault breccia are structure elements within the fault core and sets of fractures are subsidiary structures in damage zones. Modified from Gudmundsson (2005) 
human negligence, are often the cause of unpredicted inrush accidents. These hidden fault systems were the research target for this study.

A hidden fault in an underground mine is fairly small relative to the size of the entire operation and therefore can reasonably be treated as a crack. Based on this assumption, a typical model of an underground mine was established (Fig. 2) for numerical calculations and analysis.

\section{A Brief Description of Computational Fracture Mechanics}

In fracture mechanics, a crack is defined as a line of discontinuity in two dimensions, and a surface of discontinuity in three dimensions, which may be loaded in three independent ways (Bordas 2003; Kanninen and Popelar 1985): opening mode (mode I), shearing mode (mode II), and tearing mode (mode III). The stress and strain fields of the crack tip can be represented as a linear combination of each independent mode. For each loading mode, a scalar coefficient called SIF can be applied to represent the stress concentration magnitude of the tip field, where $\mathrm{K}_{\mathrm{I}}$ and $\mathrm{K}_{\mathrm{II}}$ and $\mathrm{K}_{\mathrm{III}}$ refer to the SIF of modes I, II, and III respectively. If a crack is loaded in two or three modes, then the corresponding two or three SIFs are needed to represent the crack tip fields.

We assumed that geostatic pressure acts on the vertical direction and tectonic pressure acts on the horizontal direction of the modeled hidden fault in Fig. 2. Due to

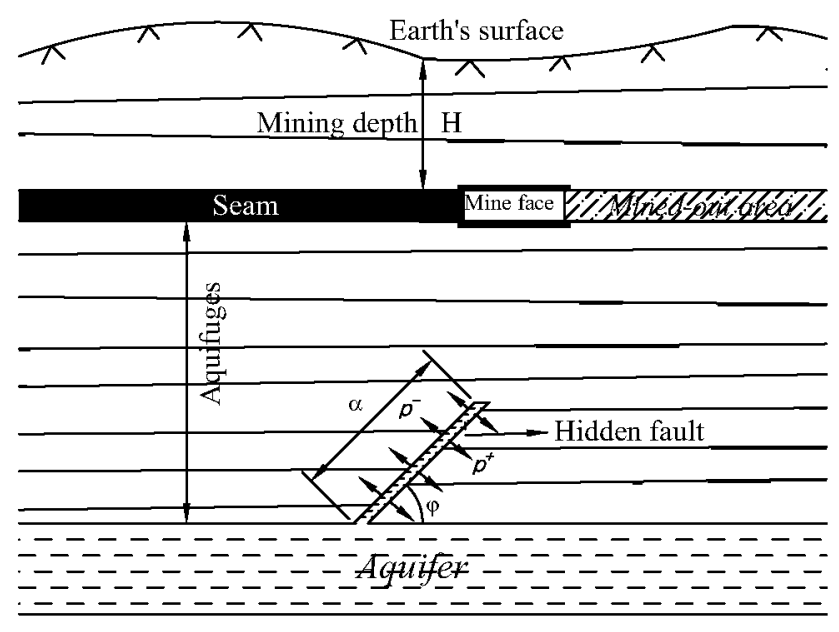

Fig. 2 A typical underground mining model, in this model, the aquifer which is connected with a fault is located in the floor strata, a and $\phi$ are the length and the dip angle of the fault respectively, $p$ is the fluid seepage pressure and we assume that all strata between the seam and the aquifer are aquifuges the dip angle of the fault, components of these pressures exert both compressive and shear stress. It is difficult to directly compute crack tip fields using traditional fracture mechanics because the SIFs must be calculated for each mode by decomposing the loads. To manage this, XFEM can be used to model the computation of the crack tip fields and SIF.

\section{A Brief Introduction to XFEM}

\section{The Basic Formulation}

XFEM was introduced by Belytschko and Black (1999) to solve problems in which discontinuities are present without remeshing the framework. It eliminates the difficulties of high-density grid meshing in which stress is concentrated. Based on the partition of unity method (PUM, as proposed by Melenk and Babuska 1996), XFEM simulates cracks by enriching the shape functions of the elements involved in the formulation of the classical FEM approach. The "step" function and the function of asymptotic displacement field near the crack tip were introduced by Nicolas et al. (1999) to describe crack surfaces and crack tips. For linear elastic problems, when an element is involved in crack simulation, the approximation of the displacements can be represented as the sum of the displacement obtained by the classical FEM $\mathrm{u}^{\mathrm{FE}}$ and the enriched displacement $\mathrm{u}^{\mathrm{en}}$ as follows:

$$
\mathbf{u}(\mathbf{x})=\mathbf{u}^{\mathrm{FE}}+\mathbf{u}^{\mathrm{en}}=\sum \underbrace{\mathrm{N}_{i}(x) u_{i}}_{i \in N}+\sum \underbrace{\mathrm{N}_{\mathrm{i}}(\mathbf{x}) \phi(\mathbf{x}) \mathbf{a}_{\mathrm{i}}}_{\mathrm{i} \in \mathrm{N}_{\Gamma} \cup \mathrm{N}_{\wedge}}
$$

where $u_{i}$ is the classical FEM nodal displacement approximation, $\mathrm{N}$ is the total number of the nodes, $\mathrm{N}_{\mathrm{i}}$ refers to the shape function of the corresponding node i, $N_{\Gamma}$ is the set of nodes of elements that are cut by crack surface

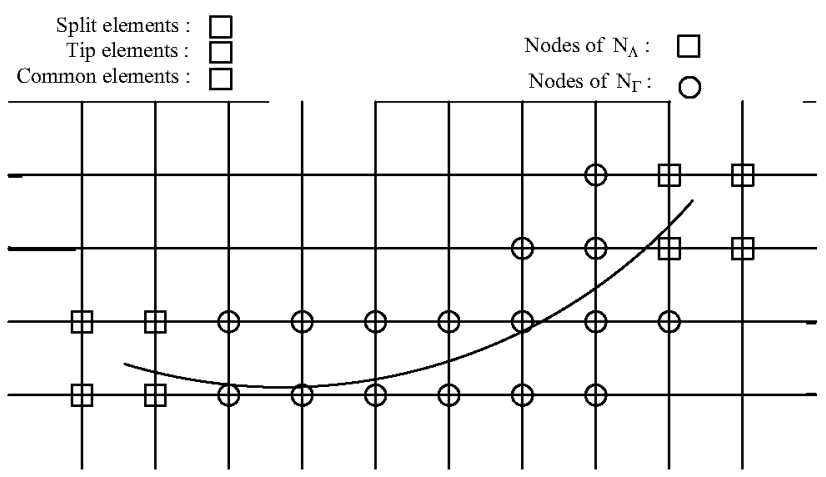

Fig. 3 Elements and nodes enrichment scheme for quadrilateral elements crossed by a crack, squares show the crack tip enrichment, and circles are related to the Heaviside enrichment 
(nodes shown in Fig. 3 with circles), $N_{\wedge}$ is the set of nodes cut by crack tip (nodes shown in Fig. 3 with rectangles), $\phi(x)$ represents the associated enrichment function and $a_{i}$ stands for the enriched degrees of freedom (DOF) of the displacement.

For crack problems, Eq. 1 can be further written as:

$\mathbf{u}(\mathbf{x})=\mathbf{u}^{F E}(\mathbf{x})+\mathbf{u}^{H}(\mathbf{x})+\mathbf{u}^{\text {tip }}(\mathbf{x})$

where $\mathbf{u}^{\mathrm{H}}(\mathbf{x})$ refers to the DOF of the nodes associated with the crack surfaces and $\mathbf{u}^{\text {tip }}(\mathbf{x})$ refers to the DOF of the nodes associated with the crack tips. The Eq. 1 can be rewritten as (Zi and Belytschko 2003):

$\mathbf{u}(\mathbf{x})=\sum \underbrace{\mathrm{N}_{\mathrm{i}}(\mathbf{x}) \mathbf{u}_{\mathrm{i}}}_{\mathrm{i} \in \mathrm{N}}+\sum \underbrace{\mathrm{N}_{\mathrm{i}}(\mathbf{x}) \mathrm{H}(\mathbf{x}) \mathbf{a}_{\mathrm{i}}}_{\mathrm{i} \in \mathrm{N}_{\Gamma}}+\sum \underbrace{\mathrm{N}_{\mathrm{i}}(\mathbf{x})\left(\sum_{l=1}^{4} \mathrm{~F}_{1}(\mathbf{x}) \mathbf{b}_{\mathrm{i}}^{l}\right)}_{\mathrm{i} \in \mathrm{N}_{\Lambda}}$

where $a_{i}$ and $b_{i}^{l}$ represent the enriched DOFs associated with crack surfaces and crack tips, $H(x)$ refers to the Heaviside "step" function and takes the values +1 and -1 depending on the side of the crack, that is:

$\mathbf{H}(\varepsilon)= \begin{cases}1 & \forall \varepsilon>0 \\ -1 & \forall \varepsilon \leq 0\end{cases}$

$F_{l}(x)$ is a set of functions, which are obtained from the asymptotic displacement field near the crack tip. It reflects the singularity of tip fields and can be expressed as a linear combination of the following functions:

$$
\begin{aligned}
F(r, \theta)= & \left\{r^{\lambda} \sin (\lambda \theta), r^{\lambda} \cos (\lambda \theta), r^{\lambda} \sin (\theta) \sin (\lambda \theta),\right. \\
& \left.r^{\lambda} \sin (\theta) \cos (\lambda \theta)\right\}
\end{aligned}
$$

where the parameters $r$ and $\theta$ are defined in polar coordinates (Fig. 4). The value of $\lambda$ depends on the crack's properties. In general, if there is no fluid within the crack, $\lambda=1 / 2$; however, if the crack is filled with fluid, then the value of $\lambda$ is associated with the fluid's viscosity and the toughness of the crack (see Garagash and Detourmay 2000; Desroches et al. 1994; Detournay 2004). In this work, the value of $\lambda$ was taken as $2 / 3$ since the crack was filled with water.

Fracture mechanics analyses based on XFEM are, so far, mainly limited to cracks with no surface traction. However, in this study, fluid pressure on the crack surfaces must be considered because of its effect on crack growth and stability. Recent studies that solve surface loading problems using XFEM include Asferg et al. (2007), Dolbow et al. (2001) and $\mathrm{Zi}$ and Belytschko (2003). Although XFEM and the classical FEM differ in terms of displacement approximation, their governing equations are similar since they have the same discretization processes. The detailed discretization processes of

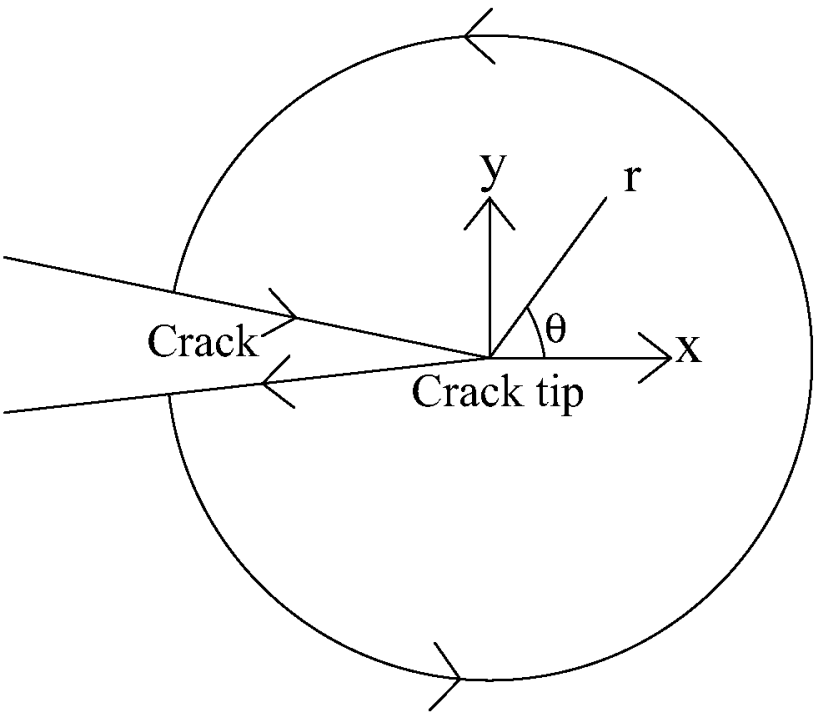

Fig. 4 Location coordinates system at the crack tip

XFEM using the principle of virtual work can be seen in Dolbow (1999) or Khoei (2014).

\section{Fracture Criterion and SIFs for a Mixed Mode Crack}

\section{Fracture Criterion}

The maximum circumferential stress criterion (Erdogan and Sih 1963) can be used to solve crack extension problems. It is based on the assumption that the crack will grow in the direction normal to the maximum circumferential stress $\sigma_{\theta \theta}$. According to elastic fracture mechanics, the circumferential stress and the tangential stress $\sigma_{r \theta}$ at the crack tip can be expressed as:

$$
\begin{aligned}
\left\{\begin{array}{c}
\sigma_{\theta \theta} \\
\sigma_{r \theta}
\end{array}\right\}= & \frac{K_{\mathrm{I}}}{4 \sqrt{2 \pi r}}\left\{\begin{array}{c}
3 \cos \left(\frac{\theta}{2}\right)+\cos \left(\frac{3 \theta}{2}\right) \\
\sin \left(\frac{\theta}{2}\right)+\sin \left(\frac{3 \theta}{2}\right)
\end{array}\right\} \\
& +\frac{K_{\Pi}}{4 \sqrt{2 \pi r}}\left\{\begin{array}{c}
-\sin \left(\frac{\theta}{2}\right)-3 \sin \left(\frac{3 \theta}{2}\right) \\
\cos \left(\frac{\theta}{2}\right)+3 \cos \left(\frac{3 \theta}{2}\right)
\end{array}\right\}
\end{aligned}
$$

By assuming $\sigma_{r \theta}=0$, the maximum circumferential stress is reached and the crack will be in a state of instability and will grow from its tip. By combining this with Eq. 6 the following expression is obtained:

$\tan \left(\frac{\theta}{2}\right)=\frac{1}{4}\left[\frac{K_{\mathrm{I}}}{K_{\Pi}} \pm \sqrt{\left(\frac{K_{\mathrm{I}}}{K_{\Pi}}\right)^{2}+8}\right]$ 
According to the hypothesis that the crack will grow in the direction perpendicular to the largest tension at the crack tip (Erdogan and Sih 1963), we can judge if a crack is stable using the following expression:

$K_{e q}=\frac{1}{2} \cos \frac{\theta_{0}}{2}\left[K_{\mathrm{I}}\left(1+\cos \left(\theta_{0}\right)-3 K_{\Pi} \sin \left(\theta_{0}\right)\right] \geqslant K_{\mathrm{I} c}\right.$

where $K_{e q}$ is the equivalent stress intensity factor, and $K_{\mathrm{Ic}}$ denotes the fracture toughness and $K_{\mathrm{I} c}$ is a quantitative way of expressing the resistance of the material to brittle fracture and has no relationship with the state of stress. Its value can only be determined by the material properties, where $\theta_{0}$ refers to the crack propagation angle, which is derived from Eq. 7.

$\theta_{0}=2 \arctan \left\{\frac{1}{4}\left[\frac{K_{\mathrm{I}}}{K_{\Pi}} \pm \sqrt{\left(\frac{K_{\mathrm{I}}}{K_{\Pi}}\right)^{2}+8}\right]\right\}$

By analyzing the fracture criterion expression (Eq. 8), we can conclude that crack stability is directly related to its SIFs at the tip. In the next section, the method of computing SIFs based on XFEM will be described.

\section{Computing SIFs with Consideration of Fluid Pressure on Crack Surfaces}

Among all of the methods for computing SIFs, the interaction integral method (Yau and Wang 1984) for solving mixed mode problems was shown to be the most accurate (Nagashima et al. 2003). According to Yan's study, the interaction integral $I^{(1,2)}$ for two states of a crack body can be expressed as:

$$
\begin{aligned}
& I^{(1,2)}=\frac{2}{E^{*}}\left(K_{\mathrm{I}}^{(1)} K_{\mathrm{I}}^{(2)}+K_{\Pi}^{(1)} K_{\Pi}^{(2)}\right) \\
&=\int_{A}\left[\sigma_{i j}^{(1)} \frac{\partial u_{i}^{(2)}}{\partial x_{1}}+\sigma_{i j}^{(2)} \frac{\partial u_{i}^{(1)}}{\partial x_{1}}-W^{(1,2)} \delta_{1 j}\right] \frac{\partial q}{\partial x_{j}} d A \\
& W^{(1,2)}=\sigma_{i j}^{(1)} \varepsilon_{i j}^{(2)}=\sigma_{i j}^{(2)} \varepsilon_{i j}^{(1)} \\
& \mathrm{E}^{*}= \begin{cases}\mathrm{E} & \text { For plane stress } \\
\frac{\mathrm{E}}{1-v^{2}} & \text { For plane strain }\end{cases}
\end{aligned}
$$

where $\sigma_{i j}^{(1)}, \varepsilon_{i j}^{(1)}$, and $u_{i}^{(1)}$ refer to the real state (state 1) and are obtained from the present XFEM calculation, $\sigma_{i j}^{(2)}, \varepsilon_{i j}^{(2)}$, and $u_{i}^{(2)}$ refer to the auxiliary state (state 2 ) and are obtained from the asymptotic fields for mode I or mode II. $E$ is Young's modulus and $v$ is Poisson's ratio. A is the integral domain and $q$ is the weight function, and the detailed definition of $\mathrm{A}$ and $\mathrm{q}$ can be seen in Dolbow and Li's studies (Dolbow et al. 2001; Li and Needleman 1985).

Once the value of the interaction integral $I^{(1,2)}$ is obtained from Eq. (10), setting the state 2 as pure Mode I asymptotic fields with $K_{\mathrm{I}}^{(2)}=1, \quad K_{\Pi}^{(2)}=0$, the stress intensity factor can be obtained for Mode I as follows:

$K_{\mathrm{I}}^{(1)}=\frac{2}{E^{*}} I^{(1, \text { mode })}$

The stress intensity factor for Mode II can be determined in a similar manner.

We must also consider the fluid pressure on crack surfaces, but the interaction integral shown in Eq. (10) represents the crack surfaces as traction-free. For this reason, Dolbow et al. (2001) improved the interaction integral method by adding an integral term for loading crack surfaces to compute the SIFs:

$$
\begin{aligned}
I^{(1,2)}= & \int_{A}\left[\sigma_{i j}^{(1)} \frac{\partial u_{i}^{(2)}}{\partial x_{1}}+\sigma_{i j}^{(2)} \frac{\partial u_{i}^{(1)}}{\partial x_{1}}-W^{(1,2)} \delta_{1 j}\right] \frac{\partial q}{\partial x_{j}} d A \\
& +\int_{\Gamma_{c}^{+}+\Gamma_{c}^{-}}\left[\sigma_{i 2}^{(1)} \frac{\partial u_{i}^{(2)}}{\partial x_{1}}+\sigma_{i 2}^{(2)} \frac{\partial u_{i}^{(1)}}{\partial x_{1}}\right] q m d S
\end{aligned}
$$

where $\mathrm{m}$ is the unit outward normal and $\Gamma_{c}^{+}+\Gamma_{c}^{-}$are the crack surfaces.

\section{Numerical Implementation and Computational Results}

As shown in Fig. 5, the established model (Fig. 2) was split as a XFEM computation mesh. The whole

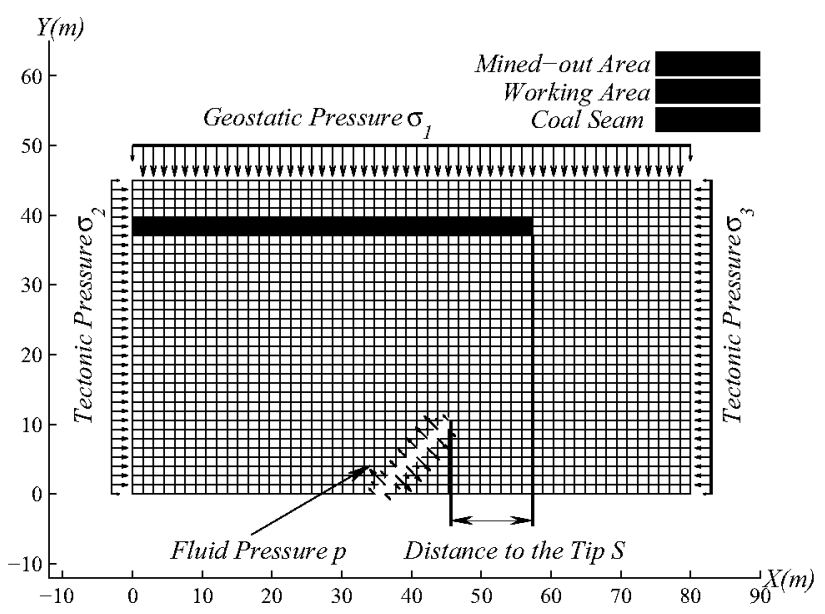

Fig. 5 Computational mesh generated based on the established model shown in Fig. 2 
computational domain was discretized into 1802 fournode elements and 1890 nodes; the computational size was $80 \mathrm{~m}$ (width) in the horizontal direction and $45 \mathrm{~m}$ (height) in the vertical direction. We assumed that the mining depth, $H=300 \mathrm{~m}$, the fault length, $a=15 \mathrm{~m}$, the fault dip angle is $\varphi=45^{\circ}$, and $p=5 \mathrm{Mpa}$ is the fluid pressure.

Based on XFEM and the knowledge of fracture mechanisms, a Matlab code was written to perform the numerical calculations. Under the assumptions of $H=300 \mathrm{~m}, a=15 \mathrm{~m}, \varphi=45^{\circ}$ and $p=5 \mathrm{MPa}$, the stress distribution of the whole computational domain is given in Fig. 6; note that the stress is the von Mises equivalent stress $\sigma_{v}$. For general plane stress condition $\left(\sigma_{3}=0, \sigma_{31}=\sigma_{23}=0\right), \sigma_{v}$ can be obtained by Eq. (15):

$\sigma_{\nu}=\sqrt{\sigma_{11}^{2}-\sigma_{11} \sigma_{22}+\sigma_{22}^{2}+3 \sigma_{12}^{2}}$

There are two main areas where the stress distributions are significant (Fig. 6). In the first, the mining-induced stresses are distributed symmetrically around the mine face and the stress concentration occurs in front of the face. The second area surrounds the fault, where significant stress concentration occurs at the fault tip.

\section{Factor Analysis}

In the computer implementation of the XFEM method, the mining depth, fault length, fault dip, and fluid pressure were used to calculate the stress fields of the fault tip. The corresponding SIFs ( $K_{\mathrm{I}}$ and $K_{\mathrm{I}}$ ) were used to represent the stress concentration magnitude of the tip field and $K_{e q}$ (Eq. 8) is the equivalent SIF obtained by combining $K_{\mathrm{I}}$ and
$K_{\Pi}$ to evaluate the magnitude of the stress concentration. If the equivalent SIF is greater than the fracture toughness $K_{\text {Ic }}$ of the strata, the fault will be activated at the tip and will extend to reach the floor of the working area, causing a water inrush incident.

To analyze how varying these four corresponding parameters $(\mathrm{H}, \mathrm{a}, \varphi$ and $p)$ influence the tip fields, which is directly related to water inrush, the values for each were varied in the Matlab code to determine the corresponding SIFs. The calculated results of how the four parameters affect the stress fields of the fault tip will be described in detail below. This will provide a quantitative way to understand which condition has the highest probability to cause fault activation and which has the highest risk of mine face inrush accidents occurring.

Assuming that $a=15 \mathrm{~m}, \varphi=45^{\circ}$ and $p=5 \mathrm{MPa}$, and varying $H$ from 50 to $300 \mathrm{~m}$, Fig. 7 shows how the SIFs vary with value of $H$. The figure can be analyzed more clearly by considering two regions. When the value of $H$ is less than $147 \mathrm{~m}$, the value of $K_{\mathrm{I}}$ is positive, which means that the stress field of the fault tip in this case is tension stress and that the effects of the geostatic and tectonic pressures are weaker than that of the fluid pressure. Therefore, in this situation, the tension stress caused by the fluid pressure is the main driving force of fault activation. In the second region, where $H$ exceeds $147 \mathrm{~m}$, both $K_{\mathrm{I}}$ and $K_{e q}$ are negative, and the tip field becomes compressive stress. $K_{\mathrm{I}}$, $K_{\Pi}$, and $K_{e q}$ increase as $\mathrm{H}$ increases, which indicates that the probability of fault activation rises and the possibility of water inrush increases as the mining depth increases.

Assuming that $a=15 \mathrm{~m}, \varphi=45^{\circ}$, and $H=300 \mathrm{~m}$ and the fluid pressure $p$ ranges from 0.5 to $5 \mathrm{MPa}$, the SIFs vary due to the change of $p$. With the increase of $p, K_{\Pi}$ gradually decreases, which indicates that the degree of
Fig. 6 Von-Mises stress contours of the whole computational domain

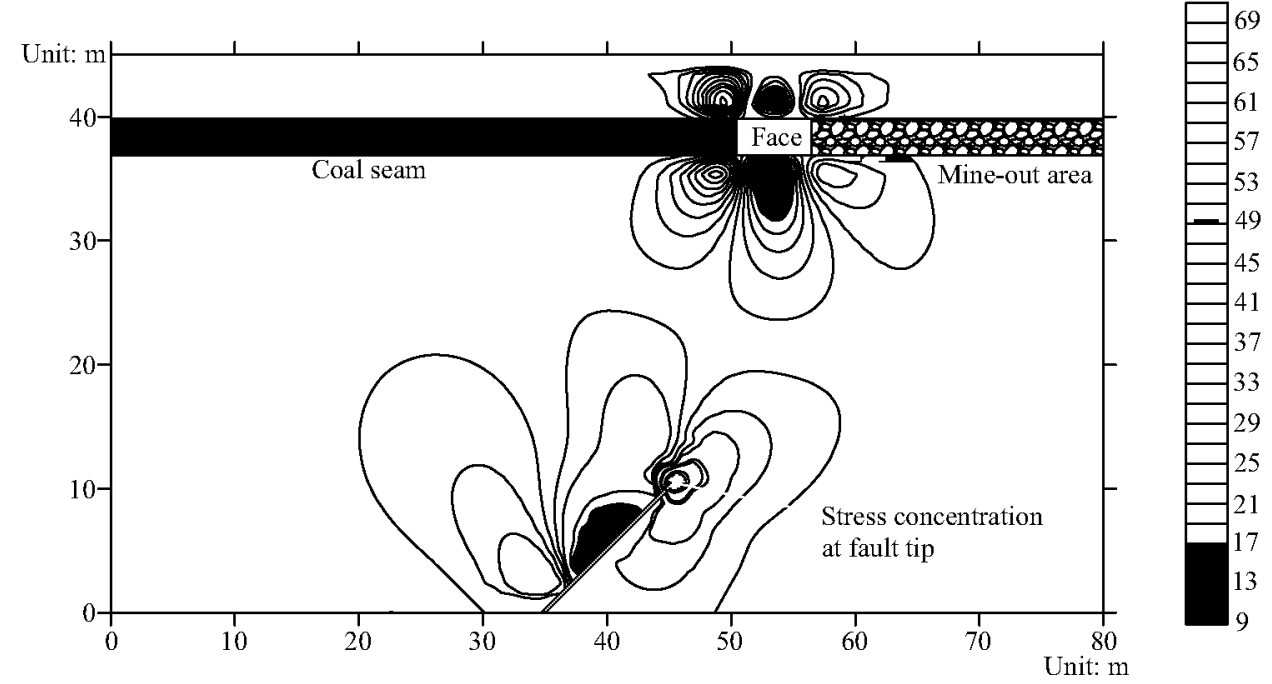


Fig. 7 Variation of SIFs due to the change of mining depth

Fig. 8 Variation of SIFs due to the change of fluid pressure
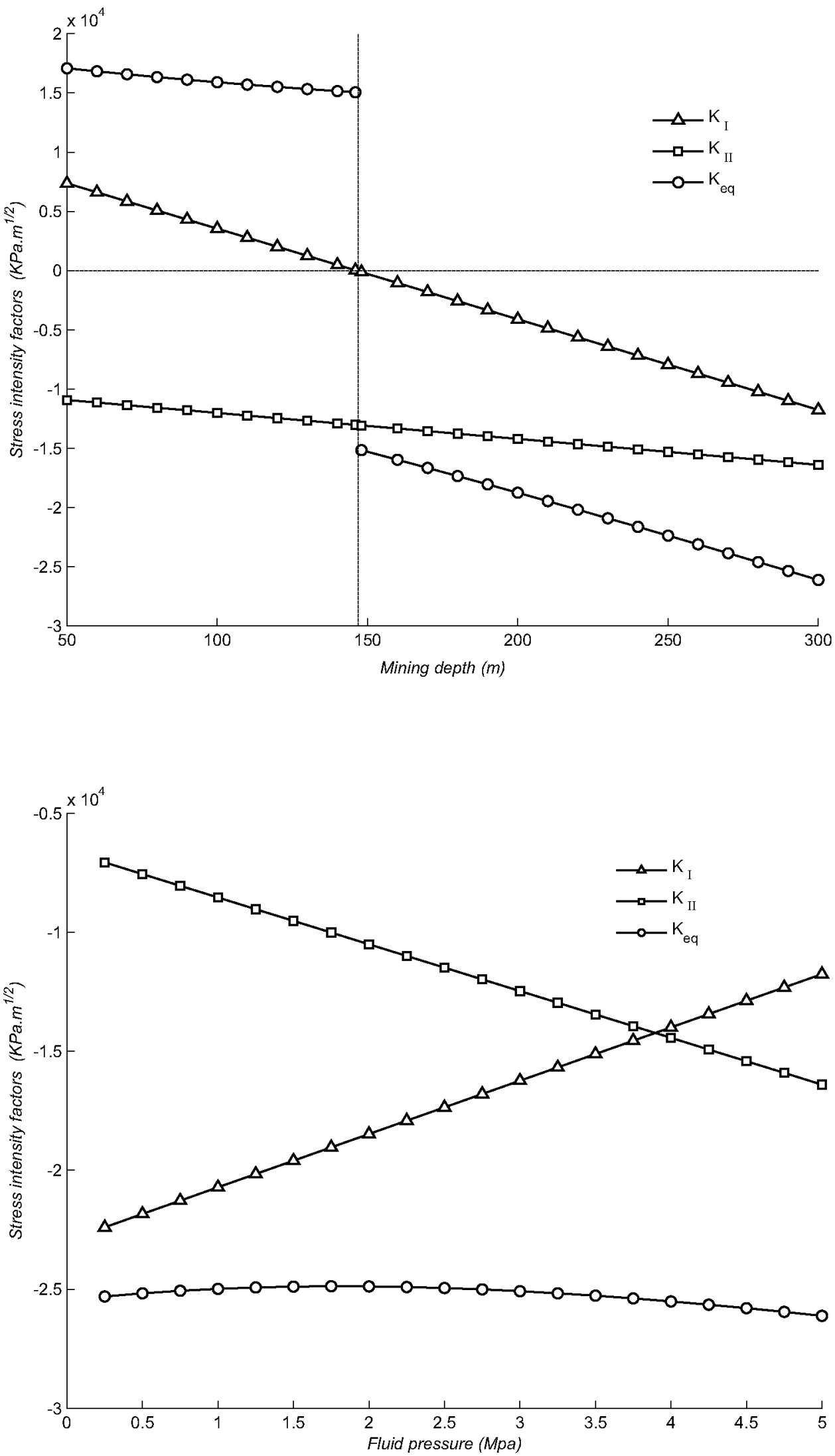
shear stress concentration continually weakens at the fault tip, and the value of $K_{\mathrm{I}}$ increases with the raise of $p$ (Fig. 8). This means that the compressive stress concentration constantly increases. From the overall trend of $K_{\mathrm{I}}, K_{\Pi}$ and based on the small changes of $K_{e q}$, it can be concluded that the higher the fluid pressure, the greater the likelihood of a compressive fracture occurring at the fault tip and the greater the possibility that water inrush will be induced by fault activation. In addition, at a low fluid pressure, a fault can also be activated at the fault tip, causing water inrush by shear stresses, because under low fluid pressure, $K_{\Pi}$ is much greater than $K_{\mathrm{I}}$.

At a mining depth, $\mathrm{H}$, of $300 \mathrm{~m}, p=5 \mathrm{MPa}$. Changing the fault dip from $10^{\circ}$ to $90^{\circ}$ and the fault length from 5 to $20 \mathrm{~m}$ to see how these two parameters impact the stress fields of the fault tip. Figure 9 shows that below $57^{\circ}$, the compressive stress concentration weakens as $\varphi$ increases, but above $57^{\circ}$, the concentration degree increases gradually until reaching $90^{\circ} . K_{\Pi}$ is reduced as the fault dip increases, which indicates that the concentration of shear stress is continually abated. When the angle approaches $90^{\circ}$, the concentration of the shear stress does not exist. Figure 10 shows how the SIFs vary with the value of a. In summary, the three SIFs have the same variation trend, namely increasing as fault length grows. This results in stronger compressive and shear stress concentrations at the fault tip as the fault length increases. Therefore, there is a higher probability of fault activation and a greater possibility of water inrush accidents.

\section{Whether the Advance of the Mine Face Will Cause Fault Activation}

Cases of sudden water inrush often occur when a mine face advances to a certain location. This is generally explained by faults under the mine face being activated by mininginduced stress. A numerical simulation was used to verify this explanation. The same quadrilateral mesh model was used as in the previous sections (Fig. 5), and $H, a, \varphi$, and $p$ were set as fixed values, $H=300 \mathrm{~m}, a=15 \mathrm{~m}, \varphi=45^{\circ}$, and $p=5 \mathrm{MPa}$. The advancing process of a mine face was simulated from right to left (Fig. 11). Different elastic modulus values were used to simulate the material properties of different elements. For example, the working area was set as air elements and the elastic modulus was set as a value that approaches zero. For the mined-out area, the elastic modulus was set as two orders of magnitude less than the coal seam because in the actual mining situation, the mined-out area is typically filled with unconsolidated and crushed rock.

When mine face advancement from right to left was simulated, the computation results of the SIFs corresponded
Fig. 9 Variation of SIFs due to the change of fault dip

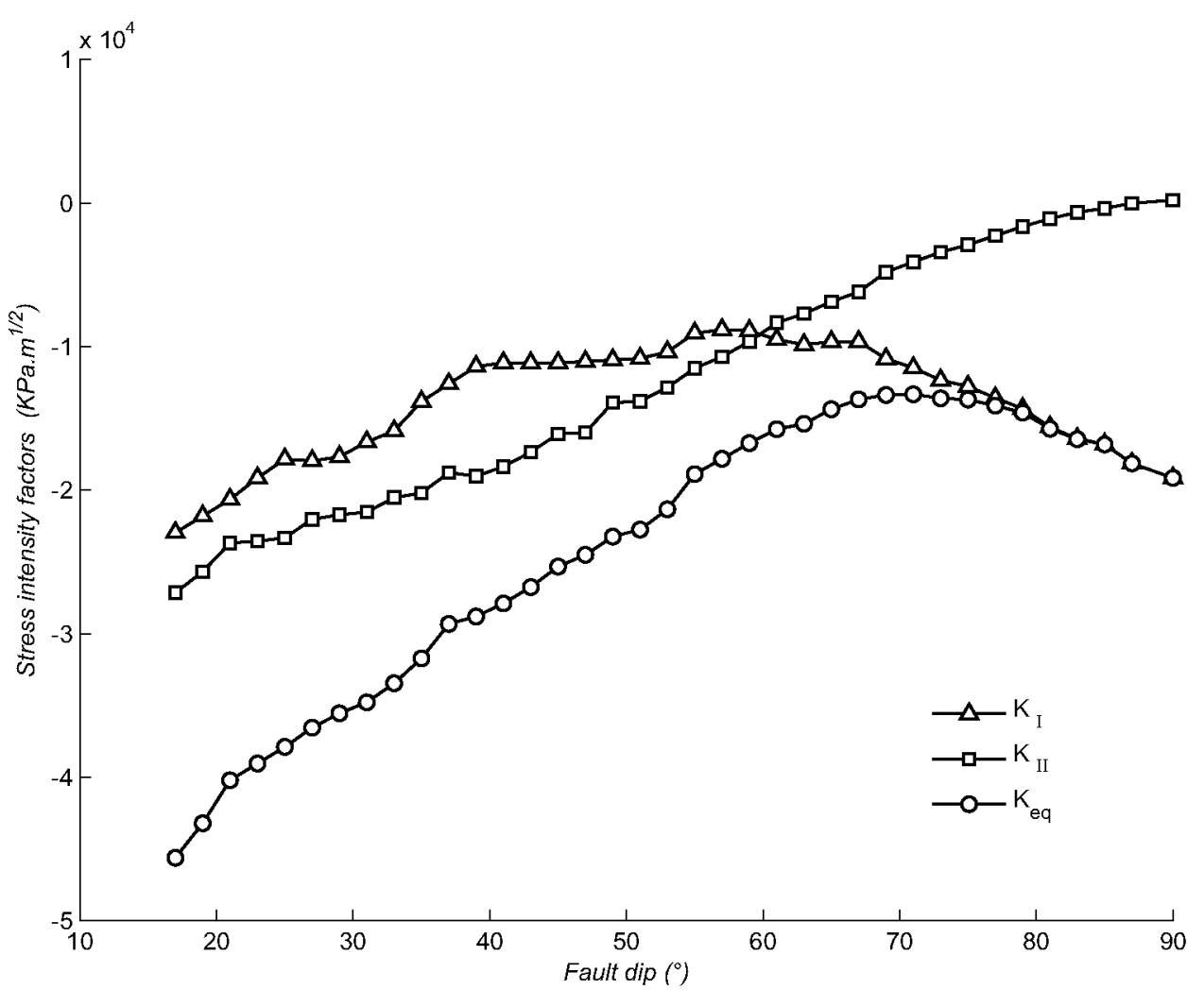


Fig. 10 Variation of SIFs due to the change of fault length

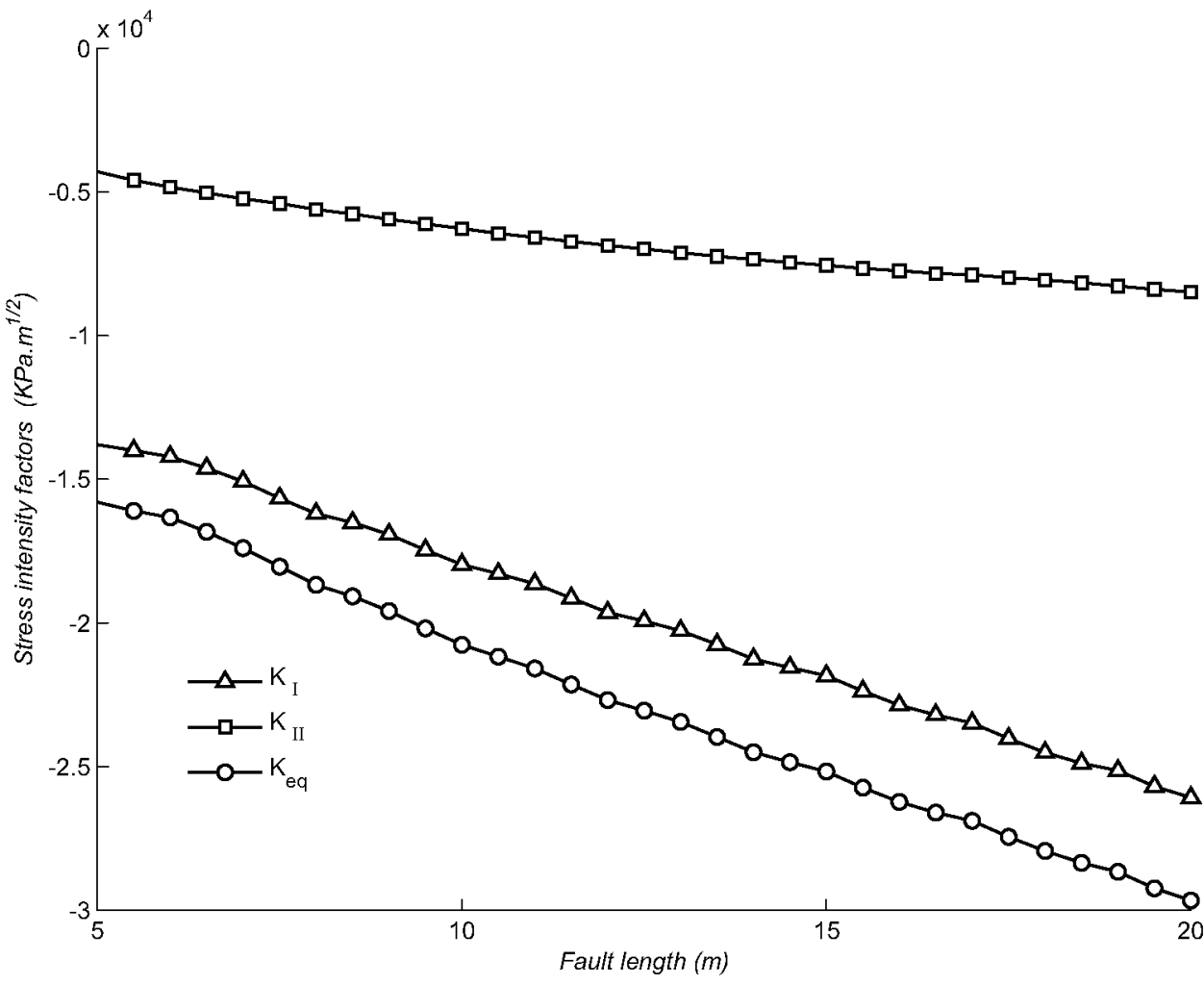

\section{A Working area is located before the fault tip}

Working area

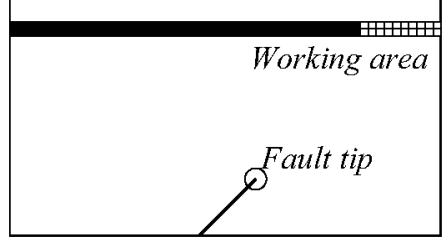

B Working area is located on the fault tip

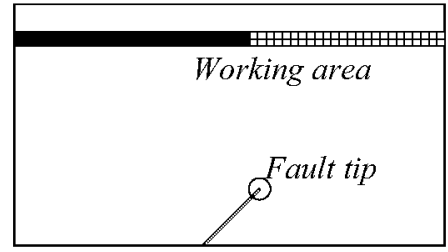

\section{Working area is located behind the fault tip}

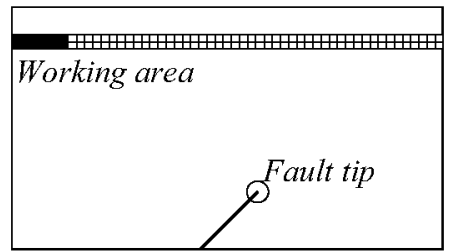

Fig. 11 The process of advancing of a mine face from left to right to where the working area was in different locations. By setting the horizontal distance $S$ (Fig. 5) as the abscissa, Fig. 12 shows how SIFs vary as the mine face advances. Note that in this figure, the abscissa is positive when the mine face is on the right side of the fault tip. The results (Fig. 12) indicate that as the face gets closer to the fault tip, $K_{\mathrm{I}}$ gradually increases and $K_{\Pi}$ gradually decreases, which indicates that the degree of compressive stress concentration is increased and the shear stress concentration is gradually abated. The $K_{e q}$, which combines $K_{\mathrm{I}}$ and $K_{\Pi}$ to evaluate the magnitude of the overall stress concentration, continually increases as the face approaches the fault tip. These results show that when the mining face gradually approaches a fault tip, stress concentration is elevated, which creates a greater possibility of fault activation and water hazards.

\section{Conclusion}

In this work, we present a novel numerical approach for modeling and understanding fault-induced water inrush underground. A numerical model of an underground stope with a hidden fault was established and XFEM and fracture mechanics were used to solve the discontinuity issues of the established model. Using the interaction integral method, the SIFs were computed to evaluate the possibilities of fault 
Fig. 12 Variation of SIFs along with the advancing of mine face
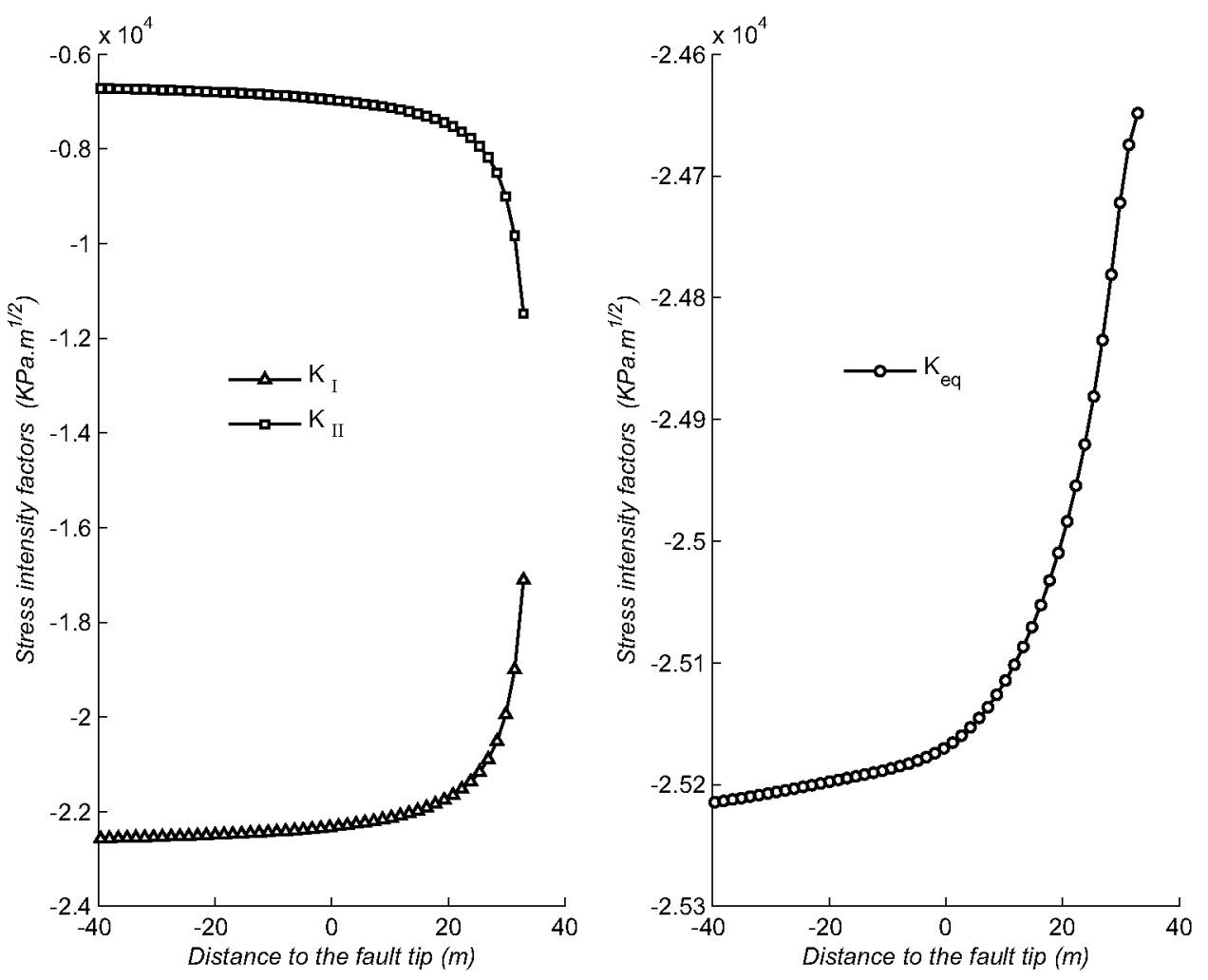

activation and water inrush. By analyzing the results of these numerical simulations, we concluded that:

1. In general, if the combined effect of geostatic and tectonic pressures exceed the fluid pressure, the possibility of water inrush increases with the mining depth.

2. Water inrushes can be induced by compressive fracture at the fault tip when fluid pressure is low or by shear fracture at the fault tip when fluid pressure is high.

3. The variation trend of $K_{\mathrm{I}}$ is shaped like a parabola, indicating that shear stress concentration is abated with an increase in dip angle. Both the compressive stress concentration and the shear stress concentration increase as the fault length increases, which increase the possibility of water inrush.

4. In addition, the results obtained in this work also demonstrate that mine face advancement can also lead to a water accident due to the overall stress concentration magnitude increase at the fault tip as the mine face approaches the tip.

It should be noted that the results obtained in this study are applicable when mining above a confined aquifer, and the main research target in this study was a small hidden fault under a working face. Therefore, it would be inappropriate to use the results of our study to analyze the risk of water inrush related to a large fault.
Acknowledgements The authors thank the China Scholarship Council (CSC) for their financial support. We are also grateful to all the reviewers and editors for their comments and suggestions.

\section{References}

Anderson TL (1995) Fracture mechanics: fundamentals and applications. CRC Press, Boca Raton

Asferg JL, Poulsen PN, Nielsen LO (2007) A consistent partly cracked XFEM element for cohesive crack growth. Int J Numer Meth Eng 72(4):464-485

Belytschko T, Black T (1999) Elastic crack growth in finite elements with minimal remeshing. Int J Numer Methods Eng 45:601-620

Bense VF, Van Balen RT (2003) Hydrogeological aspects of fault zones on various scales in the Roer valley rift system. J Geochem Explor 78-79:317-320

Bordas S (2003) Extended finite element and level set methods with applications to growth of cracks and biofilms. PhD thesis, Northwestern University, Evanston

Bu WK, Mao XB (2009) Research on effect of fault dip on fault activation and water inrush of coal floor. Chin J Rock Mech Eng 28(2):386-394 (In Chinese)

Caine JS, Evans JP, Forster CB (1996) Fault zone architecture and permeability structure. Geology 24(11):1025-1028

Chen ZH, Hu ZP (2011) Fracture mechanical model and criteria of insidious fault water inrush in coal mines. J Chin Univ Min Technol 40(5):673-677

Christophe D, Nicolas M (2000) Arbitrary branched and intersecting cracks with the extended finite element method. Int J Numer Method Eng 48:1741-1760 
Desroches J, Detournay E, Lenoach B, Papanastasiou P, Pearon JRA., Thiercelin M, Cheng AHD (1994) The crack tip region in hydraulic fracturing. Proc R Soc Lond Ser 447:39-48

Detle B (2012) Inrush and mine inundation-a real threat to Australian coal mines? In: Proc. annual conf of the international mine water assoc (IMWA), Bunbury, pp 25-29

Detournay S (2004) Propagation regimes of fluid-driven fractures in impermeable rocks. Int J Geomech 4(1):1-11

Dolbow J (1999) An extended finite element method with discontinuous enrichment for applied mechanics. Northwestern University, Evanston

Dolbow J, Moës N, Belytschko T (2001) An extended finite element method for crack growth with frictional contact. Comput Method Appl Mech 190(51-52): 6825-6846

EDI (Economic Development and Innovation) (2012) Fatalities in Queensland coal mines 1882-2012. Department of Employment, The State of Queensland, Australia

Erdogan F, Sih GC (1963) On the crack extension in plates under plane loading and transverse shear. J Basic Eng 85(4):519-527

Garagash G, Detourmay E (2000) The tip region of a fluid-driven fracture in an elastic medium. J Appl Mech 67(1):183-192

Goddard JV, Evans JP (1995) Chemical changes and fluid-rock interaction in faults of crystalline thrust sheets. Northwestern Wyoming, USA. J Struct Geol 17:533-547

Gudmundsson A (2005) Effects of mechanical layering on the development of normal faults and dykes in Iceland. Geodin Acta $18: 11-30$

Gudmundsson A, Simmenes TH, Larsen B, Philipp SL (2010) Effects of internal structure and local stresses on fracture propagation, deflection, and arrest in fault zones. J Struct Geol 32:1643-1655

Huang H, Mao X, Yao B, Pu H (2012) Numerical simulation on fault water-inrush based on fluid-solid coupling theory. J Coal Sci Eng China 18(3):291-296

Kanninen MC, Popelar (1985) Advanced fracture mechanics. Oxford Eng Science Series. Oxford Univ Press, UK

Khoei AR (2014) Extended finite element method: theory and applications. Wiley, Chichester

Li FZ, Needleman A (1985) A comparison of methods for calculating energy release rates. Eng Fract Mech 21(2):405-421

Li L, Yang T, Liang Z, Zhu W, Tang C (2011) Numerical investigation of groundwater outbursts near faults in underground coal mines. Int J Coal Geol 85:276-288

Liang DX, Jiang ZQ, Guan YZ (2015) Field research: measuring water pressure resistance in a fault-induced fracture zone. Mine Water Environ 34:320-328

Liu ZJ, Hu YQ (2007) Solid-liquid coupling study on water inrush through faults in coal mining above confined aquifer. J Chin Univ Min Technol 32(10):1046-1050

Lu Y, Wang L (2015) Numerical simulation of mining-induced fracture evolution and water flow in coal seam floor above a confined aquifer. Comput Geotech 67:157-171
Melenk JM, Babuska I (1996) The partition of unity finite element method: basic theory and applications. Comput Method Appl Mech 139 (1): 289-314

Mohammadi S (2008) Extended finite element method for fracture analysis of structure. Blackwell Publ, London

Motyka J, Bosch AP (1985) Karstic phenomena in calcareous-dolomitic rocks and their influence over the inrushes of water in lead-zinc mines in Olkusz region (South of Poland). Int J Mine Water 4:1-12

Nagashima T, Omoto Y, Tani S (2003) Stress intensity factor analysis of interface cracks using XFEM. Int. J Numer Methods Eng 56(8):1151-1173

Nicolas M, Belytschko T (2002) Extended finite element method for cohesive crack growth. Eng Fract Mech 69:813-833

Nicolas M, John D, Belytschko T (1999) A finite element method for crack growth without remeshing. Int J Numer Methods Eng $46: 131-150$

Odintsev VN, Miletenko MA (2015) Water inrush in mines as a consequence of spontaneous hydrofracture. J Min Sci 51:423-434

Przemysław B (2011) Water hazard assessment in active shafts in Upper Silesian Coal Basin Mines. Mine Water Environ 30:302-311

Rapantova N, Swiatosław K, Arnost G, Christian W (2012) Quantitative assessment of mine water sources based on the general mixing equation and multivariate statistics. Mine Water Environ $31: 252-265$

Rawling GC, Goodwin LB, Wilson JL (2001) Internal architecture, permeability structure, and hydrologic significance of contrasting fault-zone types. Geology 29(1):43-46

Sameh WAM, Broder JM (2012) Interpretation of groundwater flow into a fractured aquifer. Int J Geosci 3:357-364

Sian L, Victor B, Jenni T (2011) Fault architecture and deformation processes within poorly lithified rift sediments, central Greece. J Struct Geol 33:1554-1568

Wang JA, Park HD (2003) Coal mining above a confined aquifer. Int J Rock Mech Min Sci 40:537-555

Wu Q, Wang M, Wu X (2004) Investigations of groundwater bursting into coal mine seam floors from fault zones. Int $\mathbf{J}$ Rock Mech Min Sci 41:557-571

Yau JF, Wang SS (1984) An analysis of interface cracks between dissimilar isotropic materials using conservation integral in elasticity. Eng Fract Mech 20(3):423-432

Zhang JC (2005) Investigations of water inrushes from aquifers under coal seams. Int J Rock Mech Min Sci 42:350-360

Zhu W, Wei C (2011) Numerical simulation on mining-induced water inrushes related to geologic structures using a damage-based hydromechanical model. Environ Earth Sci 62:43-54

Zi G, Belytschko T (2003) New crack-tip elements for XFEM and applications to cohesive cracks. Int J Numer Methods Eng $57(15): 2221-2240$ 